\title{
Position Paper - Progress towards standards in integrated (aerobic) MBR modelling
}

\author{
C. Brepols 1), J. Comas 2), J. Harmand 3), M. Heran 4), Á. Robles 5), I. Rodriguez-Roda 2), M.V. \\ Ruano 5), I. Smets 6), G. Mannina 7)8) \\ 1) Erftverband, Bergheim, Germany, christoph.brepols@erftverband.de \\ 2) Catalan Institute for Water Research (ICRA) and Universitat de Girona (LEQUIA-UdG), Girona, Spain, \\ jcomas@icra.cat; irodriguezroda@icra.cat \\ 3) LBE, INRA, Univ. Montpellier, Narbonne, France, jerome.harmand@inra.fr \\ 4) Université Montpellier, Montpellier, France, marc.heran@univ-montp2.fr \\ 5) Universitat de València, Valencia, Spain, angel.robles@uv.es, m.victoria.ruano@uv.es \\ 6) KU Leuven, Leuven, Belgium, Ilse.Smets@kuleuven.be \\ 7) Engineering Department, University of Palermo, Palermo, Italy, giorgio.mannina@unipa.it \\ 8) College of Environmental Science and Engineering, Tongji University, China
}

\begin{abstract}
Membrane bioreactor models are useful tools for both design and management. The system complexity is high due to the involved number of processes which can be clustered in biological and physical ones. Literature studies are present and need to be harmonized in order to gain insights from the different studies and allow a system optimization by applying a control. This position paper aims at defining the current state of the art of the main integrated MBR models reported in the literature. On the basis of a modelling review, a standardized terminology is proposed to facilitate the further development and comparison of integrated membrane fouling models for aerobic MBRs.
\end{abstract}

Keywords: MBR modelling, integrated model, terminology

\section{Introduction}

Worldwide membrane bioreactors (MBR) are employed for aerobic wastewater treatment in a strongly increasing number of installations and larger plant capacities (Brepols et al., 2017; Xiao et al., 2019). The performance of MBR processes is driven by complex interactions between biological processes, fluid (rheological) properties and membrane filtration. The nature of the membrane feed (wastewater-biomassmatrix), membrane and module characteristics and the hydrodynamic environment influence fouling behaviour by reactor set-up and load as well as numerous operating modes (Zhang et al., 2006). Various computational models have thus been used to describe and master unit processes of MBR operations under dynamic conditions (Fenu et al., 2010; Naessens et al., 2012a, 2012b).

Despite the efforts performed in MBR-based technology modelling, this topic has not yet fully matured and needs further work. Specifically, the research community has not yet reached a general consensus about some critical issues related to the biological and physico-chemical processes and their kinetics (e.g. kinetics of soluble microbial products (SMP) formation and degradation process, precipitation processes, biodegradability in terms of high sludge retention time or aerobic/anaerobic conditions), fouling propensities of components and, consequently, to translate them into mathematical expressions (e.g. SMP modelling, influent fractionation, etc.). Furthermore, up to now, a complete, clear and generally accepted nomenclature/terminology surrounding the MBR modelling field is still lacking. This complicates comparisons among different models and impedes insights from previous applications. 
With this position paper, the IWA Task Group (TG) on Membrane Bioreactor

\section{Updated Literature Review}

Physico-chemical or mechanical unit operations. Various computational models have been used to describe and master (physico-chemical or mechanical) unit processes of MBR operations under dynamic conditions. Simple mechanistic approaches have been used to model energy consumption of MBRs based on heuristic rules and models on pumping and aeration energy (Verrecht et al., 2008). Although they can provide information on various design options, these models generally do not predict filtration performance based on membrane fouling.

Biodegradation. Activated sludge models (ASM) are well established and widely used (Langergraber et al., 2004; Rieger et al., 2013) and have been applied to simulate biomass kinetics in MBR systems (Fenu et al., 2010). Additional sub-processes or complementary models on different or additional biological pathways can be implemented to describe e.g. greenhouse-gas (GHG) emissions (Mannina et al., 2018; Massara et al., 2018; Wisniewski et al., 2018) and energy consumption (Grau et al., 2007). ASMs have also been modified to include the presence and fate of Soluble Microbial Products (SMPs) which allegedly play an important role in membrane fouling, in so-called hybrid ASM models (Zuthi et al., 2012). Hybrid ASM models could also be used to model the fate of extracellular polymeric substances (EPS) or diluted organic matter.

Filtration. Different MBR models have been focusing on the physical aspects of the fouling process by various methods with the aim of describing several processes involved in membrane fouling. Among them, mathematical models are the most widely developed which include empirical hydrodynamic models, conventional mass transfer and tangential filtration models; fractal permeation models, sectional resistance models and RIS Models (Chang et al., 2009; Naessens et al., 2012a; Ng and Kim, 2007).

Regarding the number of publications, RIS models seem to be highly popular. Based on an application of Darcy's law non-stationary mathematical equations are used to describe the total hydraulic resistance. The filtering system (physical 
membrane plus internal and external fouling) is characterized by different resistance contributions which can be correlated to local parameters (cross flow velocity, MLSS concentration, etc.), the resistances to filtration and the viscosity of a Newtonian fluid. Usually, fouling analysis is based on a quantification of the total resistance as sum of different resistances-in-series, each related to a specific fouling mechanism: the socalled resistance decomposition (Di Bella and Di Trapani, 2019).

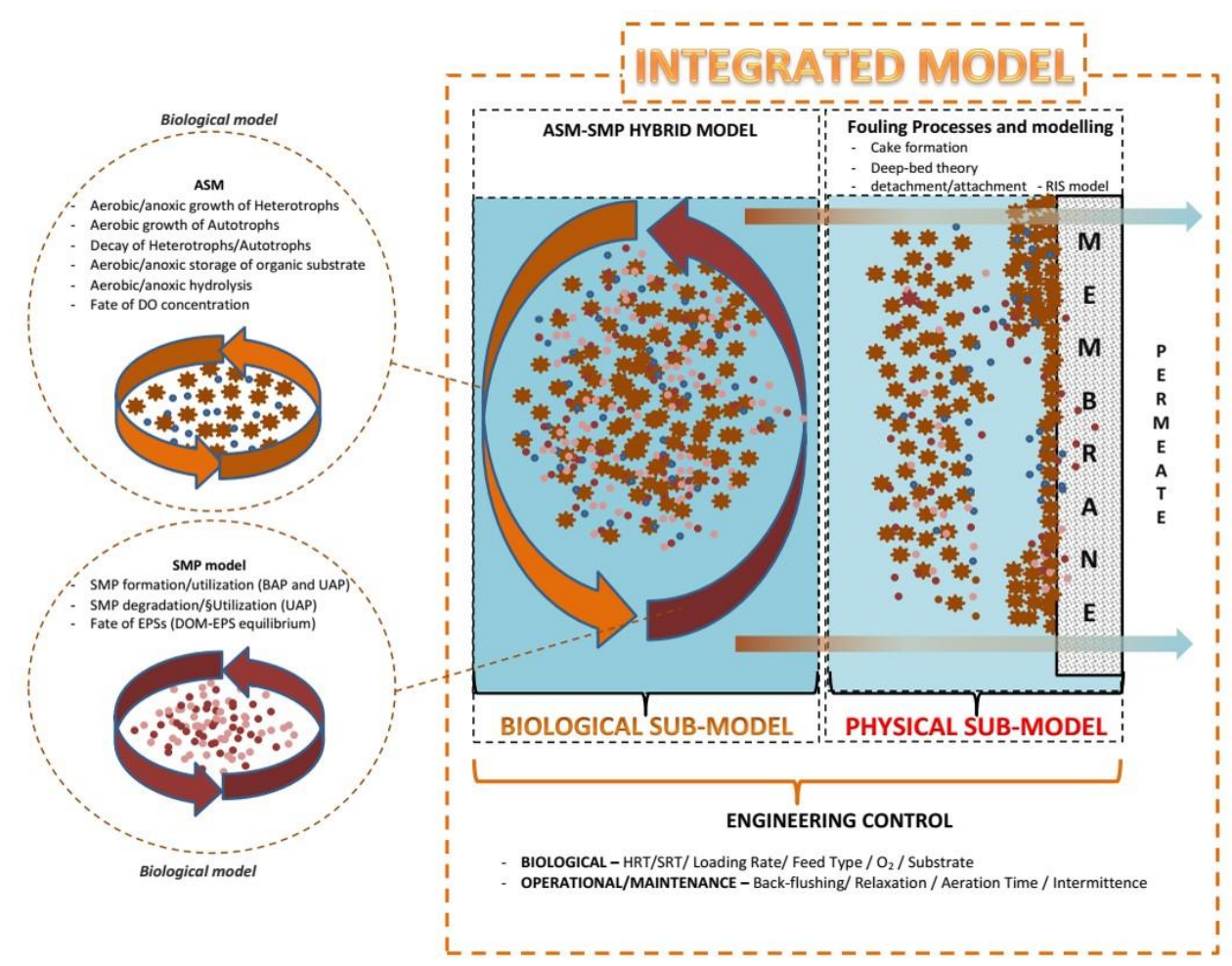

Figure 1 Integrated approach for MBR modelling (RIS: Resistance in Series, HRT: hydraulic retention time, SRT: sludge retention time.

When applied to MBR with activated sludge, the RIS concept should be used with caution (Chang et al., 2009), because the complex living suspension is not easily represented by simple addition of resistances and the additivity of components often cannot be found. Furthermore, various complementing or competing concepts on fouling phenomena in MBR have to be acknowledged (e.g.: superficial cake deposition, deep-bed fouling, complete or partial pores clogging). The analytical detection and identification of foulants is challenging. Fouling classifications and fouling mechanisms reported in literature highlight the diverse nature of membrane fouling: reversible, irreversible, irremovable fouling and cake layer deposition, intermediate blocking, concentration polarization, pore blocking, pore narrowing etc. Predicting the long-term filtration performance is further complicated by the applied membrane cleaning strategies, and by the wide range of physical scales of the examined MBR systems (Di Bella et al., 2018; Drews, 2010; Wang et al., 2014).

Computational fluid dynamics (CFD) modelling in the wastewater treatment (WWT) field is continuing to grow and is used to solve increasingly complex problems. CFD models have been used to describe various aspects of the MBR filtration process (Naessens et al., 2012b) at different scales, from entire WWTPs (Brannock et al., 2009) to microscopic levels (Lohaus et al., 2018), such as the importance of fluid 
dynamics for MBR fouling mitigation (Böhm et al., 2012; Liu et al., 2019) or optimization of MBR design and operation (Liu et al., 2018). A proposal towards good modelling practice has been described by (Wicklein et al., 2016).

Integrated models. Combinations of hybrid models with physical filtration models (mostly RIS models) have been denoted as integrated models (Mannina et al., 2011; Zuthi et al., 2013). These models allow combined simulations of several of the above mentioned crucial aspects that are important in MBR operations (Table 1). Currently these models seem to represent the most complete and complex level for the modelling of MBR systems, considering interactions among the different parts of the system (see Figure 1), despite their limitations.

Table1 Feature comparison of selected MBR modelling studies using an integrated RIS model approach

\begin{tabular}{|c|c|c|c|c|c|c|c|c|c|c|}
\hline $\begin{array}{l}\text { Reference / } \\
\text { Model features }\end{array}$ & 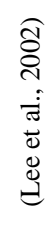 & 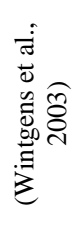 & 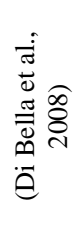 & 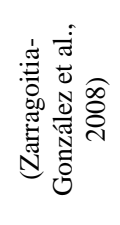 & 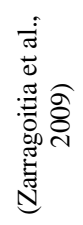 & 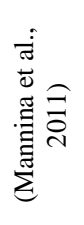 & 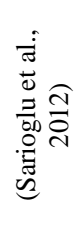 & 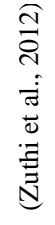 & 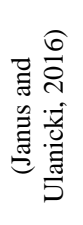 & 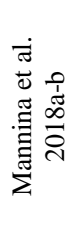 \\
\hline \multicolumn{11}{|l|}{ Biological sub-model } \\
\hline Biomass growth (e.g. $X_{\text {TSs }}$ ) & & & & $\mathrm{x}$ & $\mathrm{x}$ & & $\mathrm{x}$ & $\mathrm{x}$ & & $\mathrm{x}$ \\
\hline ASM (SMP hybrid) & $\mathrm{x}$ & $\mathrm{x}$ & $\mathrm{x}$ & & & $\mathrm{x}$ & & & $\mathrm{x}$ & $\mathrm{x}$ \\
\hline SMP & $\mathrm{x}$ & & $\mathrm{x}$ & $\mathrm{x}$ & & $\mathrm{x}$ & & $\mathrm{x}$ & & $\mathrm{x}$ \\
\hline EPS & & & & & & & & & $\mathrm{x}$ & $\mathrm{x}$ \\
\hline \multicolumn{11}{|l|}{ Process sub-models } \\
\hline Process control & & & & $\mathrm{x}$ & $\mathrm{x}$ & & & & $\mathrm{x}$ & \\
\hline Energy & & $\mathrm{x}$ & & & & & & & $\mathrm{x}$ & $\mathrm{x}$ \\
\hline \multicolumn{11}{|l|}{ Experimental set-up } \\
\hline Lab-scale & & & & & $\mathrm{x}$ & $\mathrm{x}$ & & $\mathrm{x}$ & & \\
\hline Pilot-scale & & & $\mathrm{x}$ & & $\mathrm{x}$ & & $\mathrm{x}$ & & & $\mathrm{x}$ \\
\hline Full-scale & & $\mathrm{x}$ & & & & & & & & \\
\hline Short time series ( $<1$ week) & & $\mathrm{x}$ & & & & & $\mathrm{x}$ & & & \\
\hline Long time series (> 1 week) & & $\mathrm{x}$ & $\mathrm{x}$ & & & $\mathrm{x}$ & $\mathrm{x}$ & $\mathrm{x}$ & & $\mathrm{x}$ \\
\hline \multicolumn{11}{|l|}{ Calibration method } \\
\hline heuristic & & $\mathrm{x}$ & & & & & $\mathrm{x}$ & $\mathrm{x}$ & & \\
\hline $\begin{array}{l}\text { stochastic } \\
\text { (e.g. sensitivity analysis) }\end{array}$ & & & & & & $\mathrm{x}$ & & $\mathrm{x}$ & & $\mathrm{x}$ \\
\hline
\end{tabular}

Alternative models are based on particle size distribution (PSD). Given that the cake layer on the membrane consists of deposited particles of which the submicron sized particles have a negative effect on the structure and porosity of the layer, models are proposed that take into account the particle size distribution and its impact on cake 
layer build up and the resulting membrane fouling (Broeckmann et al., 2006; Cao et 2013; Yoon et al., 1999). Due to the complex and somehow still unknown mechanisms for fouling development, there have been also approaches for data-driven modelling of fouling in MBRs (Ahmad Yasmin et al., 2017; Araujo Pimentel et al., 2016; Dalmau et al., 2015; Schmitt and Do, 2017).

Model based control. Several other authors have theoretically analysed and experimentally validated energy savings of different types of advanced control in aerobic MBR technology based on models or knowledge based approaches (Drews et al., 2007; Ferrero et al., 2011; González et al., 2018; Huyskens et al., 2011; Monclús et al., 2012; Villarroel et al., 2013). Process improvements and optimized MBR control strategies (improvement of effluent quality, reduction of fouling and energy costs) can be achieved through model-based methodologies (Kalboussi et al., 2018; Odriozola et al., 2017; Yusuf et al., 2016). Different open-loop and closed-loop control systems have thus been developed and validated for MBRs, even at full-scale (Smith et al., 2006; Vargas et al., 2008; Vera et al., 2014). Model-based approaches are a cost-efficient means to explore operational strategies for both control of biological processes (e.g. nitrification/denitrification) and membrane filtration (Perera et al., 2017; Robles et al., 2014; Sun et al., 2016). Additionally, model-based optimizations are tools in sensitivity and uncertainty analysis of the MBR process operation.

Depending on their experimental set-up, the spatial and temporal scale and the intention of their work authors promote various concepts for fouling modelling or RIS aggregation (see Table 1). The abovementioned papers reveal difficulties in identifying filtration resistances, their combinations and dynamics. Model calibration methods are not likely to be documented or are carried out on constrained data-sets. Models are seldom validated on alternative set-ups or time-lines. Uncertainties in experimental set-ups, analytical methods and model assumptions are generally not evaluated or discussed (Mannina and Di Bella, 2012; Mannina et al., 2017).

\section{Terminology and Notation}

Terminologies and notations of model parameters are a source of difficulties in comparing concepts and results across reported models. RIS models show overlaps and inconsistencies in their model nomenclature (Di Bella and Di Trapani, 2019), terminology among these models can be ambiguous. These findings resemble the conclusions from an earlier examination of activated sludge models (Corominas et al., 2010; Rieger et al., 2013). It is thus attempted to draw outlines of a notational framework within this paper, while a full and unabridged framework description would exceed the limits of this publication. Still this draft is meant to be undemanding, distinctive, complete and flexible towards future requirements.

One group of state variables is used to describe bulk components which are relevant in the model and which are used in the mass balances of the model. When variables are derived from the biological (ASM) model it is recommended that their notational framework follows existing guidelines (Rieger et al., 2013). In integrated MBR models these are usually linking elements between the biological and filtration model. They can be discriminated by their nature and particle size as well as their degradability, their organic or inorganic origin, the name of the compound and other specifications. Components, which are responsible for membrane fouling can be 
distinguished by their actual size and nature, between particulate, colloidal and soluble compounds whose definition may depend on the actual pore-size, permeation and separation characteristics of the membrane filters in use. It is thus important that particle sizes which are relevant for the underlying theories on fouling and the model are clearly specified in the model documentation. Lumped state variables which can be obtained by grouping several variables as e.g. the total suspended solids concentration $\mathrm{X}_{\mathrm{TSS}}$, eventually need to be discriminated from composite variables which are used to compare model data with experimental data. Table 2 exemplifies the framework. Variables can be named by their main symbol and a lineage of comma-separated subscripts.

Table 2: Notation of state variables describing bulk components

\begin{tabular}{|c|c|c|c|c|}
\hline $\begin{array}{l}\text { Main symbol } \\
\text { Size }\end{array}$ & $\begin{array}{l}\text { Subscript } \\
\text { correction factor }\end{array}$ & Nature & Name of compound & Specifications \\
\hline $\begin{array}{l}\text { X - particulate; } \\
\text { C - colloidal; } \\
\text { S - soluble }\end{array}$ & $\begin{array}{l}\mathrm{U} \text { - undegradable } \\
\mathrm{B} \text { - biodegradable } \\
\mathrm{A} \text { - abiotically convertible }\end{array}$ & $\begin{array}{l}\text { Org -organic, } \\
\text { Ig - inorganic }\end{array}$ & $\begin{array}{l}\text { e.g. } \\
\text { TSS } \\
\text { EPS } \\
\text { SMP }\end{array}$ & $\begin{array}{l}\text { e.g. } \\
\text { Origin, size-compartment, } \\
\text { Sub-compound, } \\
\text { valence }\end{array}$ \\
\hline
\end{tabular}

\section{Notation of Filtration Resistances}

RIS models generally employ more or less large numbers of additive resistances which are distinguished according to the applied theories on membrane fouling. Di Bella and Di Trapani (2019) provided a list of some of the most abundant resistances presented in the technical literature and come to the conclusion that despite many of the reported resistances have the same definition, they are identified with a different nomenclature due to the specific approach used. Furthermore, in some cases, the same nomenclature has been adopted to describe different fouling mechanisms. As a consequence, a more explicit notation is proposed to define the filtration resistance components of the model (Table 3). As examples intrinsic membrane resistance would be denoted $\mathrm{R}_{\mathrm{It}, \mathrm{M}}$ and reversible cake layer resistance depending on TSS concentration could be denoted as $\mathrm{R}_{\mathrm{Rv}, \mathrm{CL}, \mathrm{TSS}}$. Other model parameters describe physical and chemical bulk properties, like viscosity or $\mathrm{pH}$-value while other state variables describe filtration properties like flux, TMP, permeability. The main symbol can be used to specify the parameter or correction factors, while a lineage of subscripts can be used to specify, compound or reaction products and other specifications. Model parameters like hydrodynamic variables, rate coefficients and reduction factors require a notational frame of their own.

Table 3: Proposed notation of subscripts for filtration resistance R in RIS models

\begin{tabular}{llll}
\hline Classification & Mechanism & $\begin{array}{l}\text { Element, compound, state } \\
\text { variable }\end{array}$ & Further specification \\
\hline Intrinsic - It & Membrane - M & TSS & Origin \\
Irreversible - Iv & Cake layer formation - CL & EPS & Compartment \\
Irremovable - Im & Intermediate blocking - IB & SMP & Sub-compound \\
Reversible - Rv & Concentration polarisation - CP & & \\
& Pore blocking - PB & & \\
& Pore narrowing- PN & \\
\hline
\end{tabular}




\section{Conclusions and future perspectives}

A common RIS model framework does not exist so far. The development of a mutually accepted notation framework is thus a step towards improved exchange between researchers, modellers and practitioners longing to apply MBR models. However, the outline of a notational framework as proposed here for the biodegradation related state variables and the different resistances in the RIS based filtration model, is still a work in progress.

In accordance with previous conclusions (Naessens et al., 2012b) it can be stated that also RIS simulation studies show weaknesses regarding a good modelling practice and uncertainties in MBR modelling have not been addressed systematically. Uncertainties in wastewater treatment modelling occur during all stages of model development beginning from the scope and definition of a project through data collection and reconciliation, plant model set-up, calibration and validation to simulation and interpretation of results (Belia et al., 2009). A structured discussion on the validity of MBR models and an evaluation of possible sources, locations and levels of uncertainties seems to be inevitable. The assessment of uncertainty for MBR models needs further application to better balance model complexity between biological and physical processes.

\section{Acknowledgements}

This work has been carried out under the umbrella of the Task Group on Membrane Bioreactor Modelling and Control of the International Water Association (IWA) (http://www.iwa-network.org/groups/membrane-bioreactor-modelling-and-control/).

\section{References}

Ahmad Yasmin, N.S., Abdul Wahab, N., Yusuf, Z., 2017. Modeling of membrane bioreactor of wastewater treatment using support vector machine. Commun. Comput. Inf. Sci. https://doi.org/10.1007/978-981-10-6502-6_42

Araujo Pimentel, G., Dalmau, M., Vargas, A., Comas, J., Rodriguez-Roda, I., Rapaport, A., Vande Wouwer, A., 2016. Validation of a simple fouling model for a submerged membrane bioreactor. IFAC-PapersOnLine 28, 737-742. https://doi.org/10.1016/j.ifacol.2015.05.031

Belia, E., Amerlinck, Y., Benedetti, L., Johnson, B., Sin, G., Vanrolleghem, P.A., Gernaey, K. V., Gillot, S., Neumann, M.B., Rieger, L., Shaw, A., Villez, K., 2009. Wastewater treatment modelling: Dealing with uncertainties. Water Sci. Technol. https://doi.org/10.2166/wst.2009.225

Böhm, L., Drews, A., Prieske, H., Bérubé, P.R., Kraume, M., 2012. The importance of fluid dynamics for MBR fouling mitigation. Bioresour. Technol. 122, 50-61. https://doi.org/10.1016/j.biortech.2012.05.069

Brannock, M.W.D., De Wever, H., Wang, Y., Leslie, G., 2009. Computational fluid dynamics simulations of MBRs: Inside submerged versus outside submerged membranes. Desalination 236, 244-251. https://doi.org/10.1016/j.desal.2007.10.073

Brepols, C., Drensla, K., Janot, A., Beyerle, L., Schäfer, H., 2017. Future perspectives for MBR applications at the erftverband. Lect. Notes Civ. Eng. https://doi.org/10.1007/978-3-319-58421$8 \_22$

Broeckmann, A., Busch, J., Wintgens, T., Marquardt, W., 2006. Modeling of pore blocking and cake layer formation in membrane filtration for wastewater treatment. Desalination 189, 97-109. https://doi.org/10.1016/J.DESAL.2005.06.018

Cao, T.A., Van De Staey, G., Smets, I.Y., 2015. Integrating activated sludge floc size information in MBR fouling modeling. Water Sci. Technol. 71, 1073-1080. https://doi.org/10.2166/wst.2015.070

Chang, I.-S., Field, R., Cui, Z., 2009. Limitations of resistance-in-series model for fouling analysis in membrane bioreactors: A cautionary note. Desalin. Water Treat. 8, 31-36. https://doi.org/10.5004/dwt.2009.687 
Corominas, L., Rieger, L., Takács, I., Ekama, G., Hauduc, H., Vanrolleghem, P.A., Oehmen, A., Gernaey, K. V, Van Loosdrecht, M.C.M., Comeau, Y., 2010. New framework for standardized notation in wastewater treatment modelling. Water Sci. Technol. https://doi.org/10.2166/wst.2010.912

Dalmau, M., Atanasova, N., Gabarrón, S., Rodriguez-Roda, I., Comas, J., 2015. Comparison of a deterministic and a data driven model to describe MBR fouling. Chem. Eng. J. 260, 300-308. https://doi.org/10.1016/j.cej.2014.09.003

Di Bella, G., Di Trapani, D., 2019. A brief review on the resistance-in-series model in membrane bioreactors (MBRs). Membranes (Basel). 9. https://doi.org/10.3390/membranes9020024

Di Bella, G., Di Trapani, D., Judd, S., 2018. Fouling mechanism elucidation in membrane bioreactors by bespoke physical cleaning. Sep. Purif. Technol. 199, 124-133. https://doi.org/10.1016/j.seppur.2018.01.049

Di Bella, G., Mannina, G., Viviani, G., 2008. An integrated model for physical-biological wastewater organic removal in a submerged membrane bioreactor: Model development and parameter estimation. J. Memb. Sci. https://doi.org/10.1016/j.memsci.2008.05.036

Drews, A., 2010. Membrane fouling in membrane bioreactors-Characterisation, contradictions, cause and cures. J. Memb. Sci. 363, 1-28. https://doi.org/10.1016/J.MEMSCI.2010.06.046

Drews, A., Arellano-Garcia, H., Schöneberger, J., Schaller, J., Kraume, M., Wozny, G., 2007. Improving the efficiency of membrane bioreactors by a novel model-based control of membrane filtration. Comput. Aided Chem. Eng. 24, 345-350. https://doi.org/10.1016/S15707946(07)80081-2

Fenu, A., Guglielmi, G., Jimenez, J., Spèrandio, M., Saroj, D., Lesjean, B., Brepols, C., Thoeye, C., Nopens, I., 2010. Activated sludge model (ASM) based modelling of membrane bioreactor (MBR) processes: A critical review with special regard to MBR specificities. Water Res. 44, 4272-4294. https://doi.org/10.1016/J.WATRES.2010.06.007

Ferrero, G., Monclús, H., Sancho, L., Garrido, J.M., Comas, J., Rodríguez-Roda, I., 2011. A knowledge-based control system for air-scour optimisation in membrane bioreactors. Water Sci. Technol. 63, 2025-2031.

Ferrero, G., Rodríguez-Roda, I., Comas, J., 2012. Automatic control systems for submerged membrane bioreactors: a state-of-the-art review. Water Res. 46(11), 3421-3433.

González, E., Díaz, O., Vera, L., Rodríguez-Gómez, L.E., Rodríguez-Sevilla, J., 2018. Feedback control system for filtration optimisation based on a simple fouling model dynamically applied to membrane bioreactors. J. Memb. Sci. 552, 243-252. https://doi.org/10.1016/J.MEMSCI.2018.02.007

Grau, P., de Gracia, M., Vanrolleghem, P.A., Ayesa, E., 2007. A new plant-wide modelling methodology for WWTPs. Water Res. 41, 4357-4372. https://doi.org/10.1016/j.watres.2007.06.019

Hamedi, H., Ehteshami, M., Mirbagheri, S.A., Rasouli, S.A., Zendehboudi, S., 2019. Current Status and Future Prospects of Membrane Bioreactors (MBRs) and Fouling Phenomena: A Systematic Review. Can. J. Chem. Eng. 97, 32-58. https://doi.org/10.1002/cjce.23345

Huyskens, C., Brauns, E., Van Hoof, E., Diels, L., De Wever, H., 2011. Validation of a supervisory control system for energy savings in membrane bioreactors. Water Res. 45, 1443-1453. https://doi.org/10.1016/J.WATRES.2010.11.001

Janus, T., Ulanicki, B., 2016. Integrated benchmark simulation model of an immersed membrane bioreactor. Process Saf. Environ. Prot. 104, 24-37. https://doi.org/10.1016/j.psep.2016.08.005

Kalboussi, N., Harmand, J., Rapaport, A., Bayen, T., Ellouze, F., Ben Amar, N., 2018. Optimal control of physical backwash strategy - towards the enhancement of membrane filtration process performance. J. Memb. Sci. 545, 38-48. https://doi.org/10.1016/J.MEMSCI.2017.09.053

Langergraber, G., Rieger, L., Winkler, S., Alex, J., Wiese, J., Owerdieck, C., Ahnert, M., Simon, J., Maurer, M., 2004. A guideline for simulation studies of wastewater treatment plants. Water Sci. Technol.

Lee, Y., Cho, J., Seo, Y., Lee, J.W., Ahn, K.-H., 2002. Modeling of submerged membrane bioreactor process for wastewater treatment. Desalination 146, 451-457. https://doi.org/10.1016/S00119164(02)00543-X

Liu, M., Yang, M., Chen, M., Yu, D., Zheng, J., Chang, J., Wang, X., Ji, C., Wei, Y., 2018. Numerical optimization of membrane module design and operation for a full-scale submerged MBR by computational fluid dynamics. Bioresour. Technol. 269, 300-308. https://doi.org/10.1016/j.biortech.2018.08.089

Liu, X., Wang, Y., Shi, Y., Li, Q., Dai, P., Guan, J., Waite, T.D., Leslie, G., 2019. CFD modelling of uneven flows behaviour in flat-sheet membrane bioreactors: From bubble generation to shear 
stress distribution. J. Memb. Sci. 570-571, 146-155.

https://doi.org/10.1016/j.memsci.2018.10.040

Lohaus, J., Perez, Y.M., Wessling, M., 2018. What are the microscopic events of colloidal membrane fouling? J. Memb. Sci. 553, 90-98. https://doi.org/10.1016/j.memsci.2018.02.023

Lu, W.-M., Hwang, K.-J., 1993. Mechanism of cake formation in constant pressure filtrations. Sep. Technol. 3, 122-132. https://doi.org/https://doi.org/10.1016/0956-9618(93)80012-G

Mannina, G., Cosenza, A., Ekama, G., 2018. Mathematical modelling of greenhouse gas emissions from membrane bioreactors: A comprehensive comparison of two mathematical models. Bioresour. Technol. 268, 107-115. https://doi.org/10.1016/J.BIORTECH.2018.07.106

Mannina, G., Di Bella, G., 2012. Comparing two start-up strategies for MBRs: Experimental study and mathematical modelling. Biochem. Eng. J. 68, 91-103.

Mannina, G., Di Bella, G., Viviani, G., 2011. An integrated model for biological and physical process simulation in membrane bioreactors (MBRs). J. Memb. Sci. 376, 56-69. https://doi.org/10.1016/J.MEMSCI.2011.04.003

Massara, T.M., Solís, B., Guisasola, A., Katsou, E., Baeza, J.A., 2018. Development of an ASM2d$\mathrm{N} 2 \mathrm{O}$ model to describe nitrous oxide emissions in municipal WWTPs under dynamic conditions. Chem. Eng. J. 335, 185-196. https://doi.org/10.1016/j.cej.2017.10.119

Monclús, H., Buttiglieri, G., Ferrero, G., Rodriguez-Roda, I., Comas, J., 2012. Knowledge-based control module for start-up of flat sheet MBRs. Bioresour. Technol. 106, 50-54. https://doi.org/10.1016/J.BIORTECH.2011.12.001

Naessens, W., Maere, T., Nopens, I., 2012a. Critical review of membrane bioreactor models - Part 1: Biokinetic and filtration models. Bioresour. Technol. 122, 95-106. https://doi.org/10.1016/J.BIORTECH.2012.05.070

Naessens, W., Maere, T., Ratkovich, N., Vedantam, S., Nopens, I., 2012b. Critical review of membrane bioreactor models - Part 2: Hydrodynamic and integrated models. Bioresour. Technol. 122, 107118. https://doi.org/10.1016/J.BIORTECH.2012.05.071

$\mathrm{Ng}$, A.N.L., Kim, A.S., 2007. A mini-review of modeling studies on membrane bioreactor (MBR) treatment for municipal wastewaters. Desalination 212, 261-281. https://doi.org/10.1016/J.DESAL.2006.10.013

Odriozola, J., Beltrán, S., Dalmau, M., Sancho, L., Comas, J., Rodríguez-Roda, I., Ayesa, E., 2017. Model-based methodology for the design of optimal control strategies in MBR plants. Water Sci. Technol. 75, 2546-2553. https://doi.org/10.2166/wst.2017.135

Park, P.-K., Lee, C.-H., Lee, S., 2006. Permeability of collapsed cakes formed by deposition of fractal aggregates upon membrane filtration. Environ. Sci. Technol. 40, 2699-2705. https://doi.org/10.1021/es0515304

Perera, M.K., Englehardt, J.D., Tchobanoglous, G., Shamskhorzani, R., 2017. Control of nitrification/denitrification in an onsite two-chamber intermittently aerated membrane bioreactor with alkalinity and carbon addition: Model and experiment. Water Res. 115, 94-110. https://doi.org/10.1016/j.watres.2017.02.019

Picioreanu, C., Kreft, J.-U., Van Loosdrecht, M.C.M., 2004. Particle-based multidimensional multispecies biofilm model. Appl. Environ. Microbiol. 70, 3024-3040. https://doi.org/10.1128/AEM.70.5.3024-3040.2004

Rieger, L., Gillot, S., Lagergraber, G., Ohtsuki, T., Shaw, A., Takacs, I., 2013. Guidelines for Using Activated Sludge Models, Scientific. ed. IWA Publishing, London.

Robles, A., Ruano, M.V., Ribes, J., Seco, A., Ferrer, J., 2014. Model-based automatic tuning of a filtration control system for submerged anaerobic membrane bioreactors (AnMBR). J. Memb. Sci. 465, 14-26. https://doi.org/10.1016/j.memsci.2014.04.012

Sarioglu, M., Insel, G., Orhon, D., 2012. Dynamic in-series resistance modeling and analysis of a submerged membrane bioreactor using a novel filtration mode. Desalination 285, 285-294. https://doi.org/10.1016/J.DESAL.2011.10.015

Schmitt, F., Do, K.-U., 2017. Prediction of membrane fouling using artificial neural networks for wastewater treated by membrane bioreactor technologies: bottlenecks and possibilities. Environ. Sci. Pollut. Res. 24, 22885-22913. https://doi.org/10.1007/s11356-017-0046-7

Shin, J., Kim, K., Kim, J., Lee, S., 2013. Development of a numerical model for cake layer formation on a membrane. Desalination 309, 213-221. https://doi.org/10.1016/j.desal.2012.10.018

Smith, P.J., Vigneswaran, S., Ngo, H.H., Ben-Aim, R., Nguyen, H., 2006. A new approach to backwash initiation in membrane systems. J. Memb. Sci. 278, 381-389. https://doi.org/10.1016/J.MEMSCI.2005.11.024

Sun, J., Liang, P., Yan, X., Zuo, K., Xiao, K., Xia, J., Qiu, Y., Wu, Q., Wu, S., Huang, X., Qi, M., Wen, X., 2016. Reducing aeration energy consumption in a large-scale membrane bioreactor: 
Process simulation and engineering application. Water Res. 93, 205-213. https://doi.org/10.1016/j.watres.2016.02.026

Vargas, A., Moreno-Andrade, I., Buitrón, G., 2008. Controlled backwashing in a membrane sequencing batch reactor used for toxic wastewater treatment. J. Memb. Sci. 320, 185-190. https://doi.org/10.1016/J.MEMSCI.2008.03.073

Vera, L., González, E., Díaz, O., Delgado, S., 2014. Application of a backwashing strategy based on transmembrane pressure set-point in a tertiary submerged membrane bioreactor. J. Memb. Sci. 470, 504-512. https://doi.org/10.1016/j.memsci.2014.07.069

Verrecht, B., Judd, S., Guglielmi, G., Brepols, C., Mulder, J.W., 2008. An aeration energy model for an immersed membrane bioreactor. Water Res. 42, 4761-4770. https://doi.org/10.1016/j.watres.2008.09.013

Villarroel, R., Delgado, S., González, E., Morales, M., 2013. Physical cleaning initiation controlled by transmembrane pressure set-point in a submerged membrane bioreactor. Sep. Purif. Technol. 104, 55-63. https://doi.org/10.1016/J.SEPPUR.2012.10.047

Wang, Z., Ma, J., Tang, C.Y., Kimura, K., Wang, Q., Han, X., 2014. Membrane cleaning in membrane bioreactors: A review. J. Memb. Sci. 468, 276-307. https://doi.org/10.1016/j.memsci.2014.05.060

Wicklein, E., Batstone, D.J., Ducoste, J., Laurent, J., Griborio, A., Wicks, J., Saunders, S., Samstag, R., Potier, O., Nopens, I., 2016. Good modelling practice in applying computational fluid dynamics for WWTP modelling. Water Sci. Technol. 73, 969-982. https://doi.org/10.2166/wst.2015.565

Wintgens, T., Rosen, J., Melin, T., Brepols, C., Drensla, K., Engelhardt, N., 2003. Modelling of a membrane bioreactor system for municipal wastewater treatment. J. Memb. Sci. 216, 55-65. https://doi.org/10.1016/S0376-7388(03)00046-2

Wisniewski, K., Kowalski, M., Makinia, J., 2018. Modeling nitrous oxide production by a denitrifyingenhanced biologically phosphorus removing (EBPR) activated sludge in the presence of different carbon sources and electron acceptors. Water Res. 142, 55-64. https://doi.org/10.1016/j.watres.2018.05.041

Xiao, K., Liang, S., Wang, X., Chen, C., Huang, X., 2019. Current state and challenges of full-scale membrane bioreactor applications: A critical review. Bioresour. Technol. 271, 473-481. https://doi.org/10.1016/J.BIORTECH.2018.09.061

Yoon, S.-H., Lee, C.-H., Kim, K.-J., Fane, A.G., 1999. Three-dimensional simulation of the deposition of multi-dispersed charged particles and prediction of resulting flux during cross-flow microfiltration. J. Memb. Sci. 161, 7-20. https://doi.org/10.1016/S0376-7388(99)00049-6

Yusuf, Z., Abdul Wahab, N., Sahlan, S., 2016. Fouling control strategy for submerged membrane bioreactor filtration processes using aeration airflow, backwash, and relaxation: a review. Desalin. Water Treat. 57, 17683-17695. https://doi.org/10.1080/19443994.2015.1086893

Zarragoitia-González, A., Schetrite, S., Alliet, M., Jáuregui-Haza, U., Albasi, C., 2008. Modelling of submerged membrane bioreactor: Conceptual study about link between activated slugde biokinetics, aeration and fouling process. J. Memb. Sci. 325, 612-624. https://doi.org/10.1016/J.MEMSCI.2008.08.037

Zarragoitia, A., Schetrite, S., Jáuregui-Haza, U.J., Lorain, O., Albasi, C., 2009. Optimization of wastewater filtration process in submerged membrane bioreactors: applicability of a dynamic model to scale up, in: Computer Aided Chemical Engineering. https://doi.org/10.1016/S15707946(09)70648-0

Zhang, J., Chua, H.C., Zhou, J., Fane, A.G., 2006. Factors affecting the membrane performance in submerged membrane bioreactors. J. Memb. Sci. 284, 54-66. https://doi.org/10.1016/J.MEMSCI.2006.06.022

Zuthi, M.F.R., Ngo, H.H., Guo, W.S., 2012. Modelling bioprocesses and membrane fouling in membrane bioreactor (MBR): A review towards finding an integrated model framework. Bioresour. Technol. 122, 119-129. https://doi.org/10.1016/J.BIORTECH.2012.04.090

Zuthi, M.F.R., Ngo, H.H., Guo, W.S., Zhang, J., Liang, S., 2013. A review towards finding a simplified approach for modelling the kinetics of the soluble microbial products (SMP) in an integrated mathematical model of membrane bioreactor (MBR). Int. Biodeterior. Biodegrad. 85, 466-473. https://doi.org/10.1016/j.ibiod.2013.03.032 